\title{
Can We Use Plasma Fibronectin Levels as a Marker for Early Diabetic Nephropathy
}

\author{
Metin OZATA, Ismail KURT*, Omer AZAL, ERol BOLU, Ahmet CORAKCI, \\ ZeYNel BEYHAN, LEVENT KARACA*, ANd MeHMEt Ali GÜNDOǦAN \\ Department of Endocrinology and Metabolism and $*$ Department of Biochemistry, \\ Gülhane School of Medicine 06018 Etlik-Ankara, Turkey
}

\begin{abstract}
Although increased plasma fibronectin (PF) levels have been found in diabetic patients with microalbuminuria, there is still controversy about its clinical implication for detecting early diabetic nephropathy. To evaluate the PF concentration as a possible marker for early diabetic nephropathy, three groups of sex-and age-matched patients were studied I) 22 insulin dependent diabetic (IDDM) patients with microalbuminuria (mean age \pm SEM: $23.3 \pm 3.6$ years, mean urinary albumin excretion rate (AER) \pm SEM: $47.1 \pm 39.5 \mu \mathrm{g} / \mathrm{min}$ ); II) 17 IDDM patients with normoalbuminuria (mean age: $23.4 \pm 4.4$ years, mean AER: $7.8 \pm 2.1 \mu \mathrm{g} / \mathrm{min}$ ) and III) 20 healthy control subjects (mean age: $22.6 \pm 4.1$ years, mean AER: $6.7 \pm 2.1 \mu \mathrm{g} / \mathrm{min}$ ). PF and urinary excretion of albumin were measured by an immunoturbidimetric method using commercially available kits (Boehringer Mannheim GMBH FRG, and Miles Lab., UK). The mean PF was significantly higher in the group with microalbuminuria $(406.5 \pm 122.9 \mu \mathrm{g} / \mathrm{ml})$ than in the group with normoalbuminuria $(295.6 \pm 96.9 \mu \mathrm{g} / \mathrm{ml}, P<0.01)$ or in the control group $(299.54 \pm 105.5$ $\mu \mathrm{g} / \mathrm{ml}, P<0.01)$. A weak positive correlation was found between $P F$ and urinary albumin values $(r=0.35$, $P<0.05)$. There were no significant correlations between $\mathrm{PF}$ and the other variables such as age, duration of diabetes, body mass index, arterial blood pressure, fasting blood glucose, fructosamine and $\mathrm{HbA} 1$ in the diabetic patients or in the control group. Our results suggest that the PF concentration could be a weak marker for early diabetic nephropathy. We cannot therefore use PF instead of microalbuminuria because there is only a weak correlation between PF and microalbuminuria.
\end{abstract}

Key words: Diabetes mellitus, Fibronectin, Early diabetic nephropathy.

(Endocrine Journal 42: 301-305, 1995)

FIBRONECTIN is a high-molecular-weight plasma glycoprotein that is mainly produced by fibroblasts and endothelial cells [1, 2]. Plasma fibronectin (PF) plays a role in erythrocyte or platelet adhesion to vascular endothelium or subendothelial collagen [3, 4].

Increased biosynthesis of fibronectin in endothelial cells and fibroblasts was reported in diabetes $[5,6]$, and it is also found in an increased amount in the capillary wall and mesangium of the glomeruli of diabetic subjects [6-8]. Glycated fibronectin

Received: June 14, 1994

Accepted: November 26, 1994

Correspondence to: Dr. Mehmet Ali GÜNDOĞAN, Dept. of Endocrinology Gülhane School of Medicine, 06018 EtlikAnkara, Turkey is characterized by altered properties, especially by decreased binding to collagen and endothelial cells [7-11]. This may contribute to disturbed vessel wall integrity $[9,11]$.

Conflicting data exist about the PF concentration in diabetic patients with microalbuminuria. In some previous studies, an increased PF concentration was found in diabetic patients with microalbuminuria [12, 13], but this was not confirmed by other investigators [3,4].

The aim of this study was to clarify this controversial issue, and to evaluate the PF concentration as a possible marker for early diabetic nephropathy. 


\section{Materials and Methods}

Thirty-seven type 1 (IDDM) diabetic patients were selected for this study. Twenty insulin-dependent diabetic patients with microalbuminuria ( 3 female, 17 male, mean age: $23.3 \pm 3.6$ years) were compared with 17 sex-and age-matched insulin dependent diabetic patients ( 3 female, 14 male, mean age: $23.4 \pm 4.4$ years) and 20 control subjects ( 3 female, 17 male, mean age: $22.6 \pm 4.1$ years). Informed consent was obtained from all patients.

Diagnosis of IDDM was done according to World Health Organization (WHO) criteria [15, 16].

Exclusion criteria included albustix positive proteinuria; blood pressure $>160 / 90 \mathrm{mmHg}$; serum creatinine $>1.4 \mathrm{mg} / \mathrm{d} l$, presence of macroangiopathy and laboratory and clinical signs of liver and renal diseases of neoplasm.

Blood samples were obtained without venostasis from patients and control subjects at $0800 \mathrm{~h}$, after a 12-h fast to determine fasting plasma glucose, glycosylated hemoglobin (HbA1), plasma fibronectin and fructosamine.

PF was measured in EDTA-plasma by an immunoturbidimetric assay with a commercially available kit (Boehringer Mannheim, FRG). Plasma samples were stored at $-70{ }^{\circ} \mathrm{C}$ until the fibronectin assays were performed.

The $\mathrm{HbA} 1$ concentration was measured by means of microcolumn chromatography at $25.5^{\circ} \mathrm{C}$ (Sigma Diagnostics, St. Louis, USA) [18].

The fructosamine concentration was measured by a modified nitroblue-tetrazolium (NBT) reduction method on a Technicon RA-1000 autoanalyzer [19].

Urinary albumin excretion, expressed as the albumin excretion rate (AER), was measured by an immunoturbidimetric method with a "Urin-pak Micro Alb immunokit" (Miles Laboratory, UK). Timed 12-h nightly urine samples were collected from the patients and control groups. At least two overnight urine samples were obtained from each patient, except for the normal subjects who delivered only one sample. The specimens were collected between $1900 \mathrm{~h}$ and $0700 \mathrm{~h}$ with written instructions to avoid exercise, but slow walking indoors was allowed. The urine volumes was measured and the albumin concentration was analyzed after centrifugation from albustix-negative samples.
AER was calculated and expressed as micrograms per minute. Normoalbuminuria was defined as urinary albumin excretion of $<15 \mu \mathrm{g} / \mathrm{min}$, microalbuminuria as $15-200 \mu \mathrm{g} / \mathrm{min}[20,31,32]$.

All the patients underwent an ophthamic examination of the fundi and fluorescin angiography of the retinal vessels, performed by an ophthalmologist unaware of the clinical details of the patients.

Blood pressure was calculated as the median value of three determinations carried out after 10 min of rest in the supine position.

The statistical method included one-way analysis of variance (ANOVA) with Duncan's studentized range test as the multiple comparison method and calculation of Pearson correlation coefficients. $P$ values $<0.05$ were considered significant. Results are expressed as the means \pm SD.

\section{Results}

Clinical details of the subjects and parameters under study are shown in Table 1 .

There was no differences between microalbuminuric and normoalbuminuric groups in the mean duration of diabetes.

Patients with microalbuminuria were characterized by significantly higher systolic blood pressure than normoalbuminuric diabetic patients or control subjects.

The mean PF concentration was much higher in the group with microalbuminuria than in the control subjects (Table 1). Moreover PF was significantly increased in the group with microalbuminuria independent of the presence of retinopathy. The PF concentration in patients with only microalbuminuria $(\mathrm{n}=18 ; 377.5 \pm 106.2 \mu \mathrm{g} / \mathrm{ml})$ was significantly higher than in the normoalbuminuric group. The mean plasma fibronectin concentration in the whole group of diabetic patients did not differ greatly from the controls $(377.5 \pm 106.2 \mu \mathrm{g} / \mathrm{m} \mathrm{l}$ versus 299.5 $\pm 105.5 \mu \mathrm{g} / \mathrm{ml}, P>0.05$, respectively).

In the whole group of diabetic patients, there was a weak positive correlation between $\mathrm{PF}$ and AER ( $\mathrm{r}=0.35, P<0.05$, Fig. 1 ).

There were no correlations between the PF concentrations and age, duration of diabetes, blood pressure, BMI, HbA1 and fructosamine. AER correlated only with systolic blood pressure (Table 2 ). 
Table 1. Characteristics of patients

\begin{tabular}{lccccc}
\hline & $\begin{array}{c}\text { Normoalbuminuric } \\
\text { group }\end{array}$ & $\begin{array}{c}\text { Microalbuminuric } \\
\text { group }\end{array}$ & $\begin{array}{c}\text { Control } \\
\text { group }\end{array}$ & F & $P$ \\
\hline $\mathrm{n}(\mathrm{m} / \mathrm{f})$ & $17(14 \mathrm{~m} / 3 \mathrm{f})$ & $20(17 \mathrm{~m} / 3 \mathrm{f})$ & $20(17 \mathrm{~m} / 3 \mathrm{f})$ & \\
Age $(\mathrm{yr})$ & $23.4 \pm 4.4$ & $23.3 \pm 3.6$ & $22.6 \pm 4.1$ & 0.23 & $P>0.05$ \\
Duration of diabetes $(\mathrm{yr})$ & $4.6 \pm 4.4$ & $4.5 \pm 3.9$ & - & - & - \\
Body mass index $\left(\mathrm{kg} / \mathrm{m}^{2}\right)$ & $21.6 \pm 2.3^{\mathrm{c}}$ & $21.4 \pm 3.6^{\mathrm{c}}$ & $24.7 \pm 3.3^{\mathrm{d}}$ & 6.69 & $P<0.05$ \\
Albumin excretion rate $(\mu \mathrm{g} / \mathrm{min})$ & $7.8 \pm 2.1^{\mathrm{h}}$ & $47.1 \pm 39.5^{\mathrm{g}}$ & $6.7 \pm 2.1^{\mathrm{h}}$ & 18.75 & $P<0.001$ \\
Systolic blood pressure $(\mathrm{mmHg})$ & $115.0 \pm 7.7^{\mathrm{f}}$ & $121.2 \pm 10.5^{\mathrm{e}}$ & $113.5 \pm 7.4^{\mathrm{f}}$ & 4.40 & $P<0.05$ \\
Diastolic blood pressure $(\mathrm{mmHg})$ & $76.5 \pm 9.3$ & $77.8 \pm 7.3$ & $70.0 \pm 8.5$ & 4.82 & $P<0.05$ \\
Retinopathy (No. of patients) & 1 & 2 & & & \\
Neuropathy (No. of patients) & 3 & 7 & & & \\
Fasting blood glucose $(\mathrm{mg} \%)$ & $184.1 \pm 71.2^{+}$ & $231.9 \pm 100.0^{+}$ & $78.4 \pm 8.5^{++}$ & 24.35 & $P<0.001$ \\
Fructosamine (mmol/L) & $3.3 \pm 0.7^{+}$ & $3.5 \pm 0.9^{+}$ & $1.6 \pm 0.3^{++}$ & 41.07 & $P<0.001$ \\
HbA1 (\%) & $10.3 \pm 2.0^{+}$ & $10.4 \pm 2.0^{+}$ & $7.0 \pm 0.7^{++}$ & 24.89 & $P<0.001$ \\
Plasma fibronectin $(\mu \mathrm{g} / \mathrm{m} l)$ & $295.6 \pm 96.9^{\mathrm{a}}$ & $406.5 \pm 122.9^{*}$ & $299.5 \pm 105.5^{\mathrm{a}}$ & 6.40 & $P<0.01$ \\
\hline
\end{tabular}

Values are means $\pm \mathrm{SD} . P<0.001$ for ${ }^{+} v s .{ }^{++}, P<0.001$ for $*$ vs. a; $P<0.05$ for $\mathrm{d} v s$. $\mathrm{c} ; P<0.01$ for e vs. f; $P<0.001$ for $g$ vs. h, Duncan's test after ANOVA.

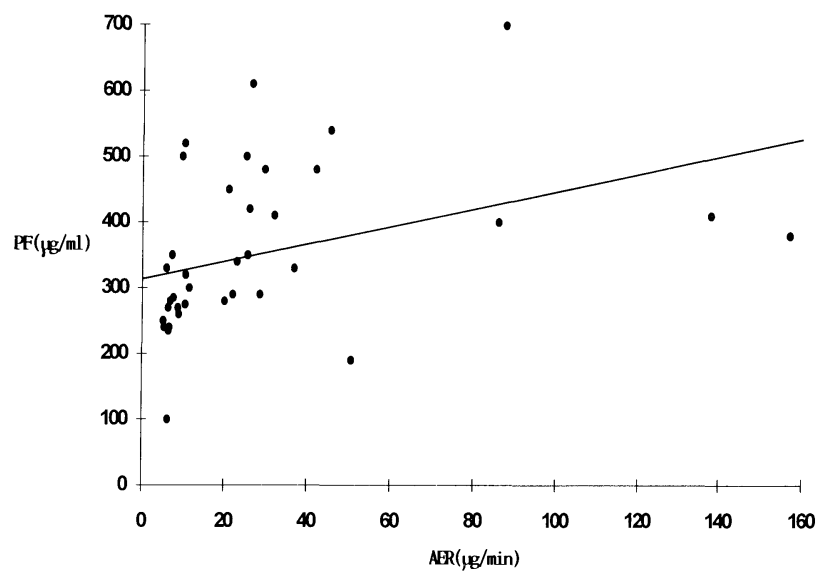

Fig. 1. Correlation of albumin excretion rate (AER) with plasma fibronectin (PF) in the whole group of diabetic patients. $Y=318.6+1.27 x ; r=0.35, P<0.05$.

\section{Discussion}

Our results showed that a high PF concentration is associated with microalbuminuria independent of the other variables considered, but there is a weak positive correlation between microalbuminuria and the PF concentration. We therefore conclude that the PF concentration could be a weak marker for early diabetic nephropathy. Our results also suggest that we cannot use the PF concentration instead of microalbuminuria for detecting early diabetic nephropathy because of this weak correlation.

In agreement with our study, DeGiorgia et al. [12] found a significant correlation between the PF concentration and microalbuminuria in patients

Table 2. Correlation of plasma fibronectin and albumin excretion rate with other variables

\begin{tabular}{lcccc}
\hline \multirow{2}{*}{ Variable } & \multicolumn{2}{c}{ Plasma fibronectin } & \multicolumn{2}{c}{ Albumin excretion rate } \\
& $\mathrm{r}$ & $P$ & $\mathrm{r}$ & $P$ \\
\hline Age & 0.2 & $\mathrm{NS}$ & 0.1 & $\mathrm{NS}$ \\
Disease duration & 0.17 & $\mathrm{NS}$ & 0.05 & $\mathrm{NS}$ \\
Body mass index & 0.24 & $\mathrm{NS}$ & 0.2 & $\mathrm{NS}$ \\
Fasting blood glucose & 0.17 & $\mathrm{NS}$ & 0.1 & $\mathrm{NS}$ \\
Fructosamine & 0.02 & $\mathrm{NS}$ & 0.1 & $\mathrm{NS}$ \\
HbA1 & 0.1 & $\mathrm{NS}$ & 0.14 & $\mathrm{NS}$ \\
Systolic blood pressure & 0.2 & $\mathrm{NS}$ & 0.46 & $<0.01$ \\
Diastolic blood pressure & 0.13 & $\mathrm{NS}$ & 0.14 & NS \\
\hline
\end{tabular}

NS: Not Significant. 
with non-insulin dependent diabetes mellitus. Although Skrha et al. [13] did not evaluate the intact plasma fibronectin, they found a positive correlation between the plasma free $\mathrm{N}$-terminal fibronectin $30-\mathrm{kDa}$ domain and albuminuria. On the other hand, Takahashi et al. [21] found increased urinary fibronectin excretion in diabetic patients with microalbuminuria.

We did not find any relationship between the PF concentration and the control of diabetes evaluated by $\mathrm{HbA1}$ and the serum fructosamine concentration. This is in close agreement with the observation of other authors [12-14, 22-24]. On the other hand, Schwartz and Scherthaner [25] found that metabolic long-term control had an effect on the PF concentration. Similarly Borkenstein et al. [26] reported a higher fibronectin concentration in diabetic children who had poorly controlled diabetes. But Davis et al. [27] reported that shortterm improved glucose control did not effect the PF concentration but the presence of diabetic microangiopathy rather than short- or long-term control of diabetes appears to be the cause of the increased plasma fibronectin concentration $[3,22$, 24]. This may be due to the dysfunction of endothelial cells in patients with diabetic micro- angiopathy [24, 28]. Increased synthesis of fibronectin in endothelial cells and fibroblast was reported in diabetes $[5,6,29]$. In our study a high fibronectin concentration may be the effect of widespread endothelial injury to small vessels. Although a recent study showed no modulation of PF function in diabetic patients receiving insulin treatment [30], some studies showed that glycated fibronectin is characterized by altered properties, especially by decreased binding to collagen and endothelial cells $[9,11]$. This may contribute to disturbed vessel wall integrity. It is therefore possible to propose that a specific role of fibronectin, originating in its binding properties, occurs during neovascularization [31]. As a result of this process, an increased plasma fibronectin could be seen as a marker of injured small vessels and angiogenesis. This is consistent with the findings of Dixon et al. [32] who found significant fibronectin deposition within the glomerular microvessel lesion of diabetic kidneys.

We conclude that the PF is a weak marker for early diabetic nephropathy, but we cannot use it instead of microalbuminuria in clinical practice because there is only a weak correlation between the two.

\section{References}

1. Jaffe EA, Masher DF (1978) Synthesis of fibronectin by cultured human endothelial cells. J Exp Med 147: 1779-1791.

2. Mosesson MN, Amrani DL (1980) The structure and biologic activities of plasma fibronectin. Blood 56: 145-158.

3. Solerte SB, Piovella F, Viola C, Carnevale GP, Gamba G, Fiovaranti M, Ferrari E (1985) Plasma fibronectin, Von Willebrand factor antigen, and blood rheology: Association with diabetic microvascular disease. Acta Diabetol Lat 22: 239-246.

4. Wautier JL, Paton C, Wauher MP, Pintigny D, Abadie E, Passa P, Caen P (1981) Increased adhesion of erythrocytes to endothelial cells in diabetes mellitus and its relation to vascular complications. $N$ Engl J Med 305: 237-242.

5. Musso R, Longo A, Cacciola RR, Lombardo A, Giustolisi R, Cacciola E (1989) Elevated fibronectin plasma levels in diabetes mellitus are expression of increased synthesis and release by vascular endothelium. Tromb Homeostasis 61: 150-151.

6. Phon-Thanh L, Robert L, Derouette JC, LabatRobert J (1987) Increased biosynthesis and processing of fibronectin in fibroblasts from diabetic mice. Proc Natl Acad Sci USA 84: 1911-1915.

7. Falk RS, Scheinman JI, Mauer Sm, Michael AF (1983) Polyantigenic expansion of basement membrane constituents in diabetic nephropathy. Diabetes 32 (Suppl 2): 34-39.

8. Monnier VM, Cerami A (1982) Non-enzymatic glycosylation and browning of proteins in diabetes. Clin Endocrinol Metab 11: 431-452.

9. Cohen MP, Ku L (1984) Inhibition of fibronectin binding to matrix components by nonenzymatic glycosylation. Diabetes 33: 970-976.

10. Krantz S, Lober M, Thiele M, Teusher E (1988) Diminished adhesion of endothelial aortic cells on fibronectin and collagen layers after nonenzymatic glycation. Exp Clin Endocrinol 91(2): 155-160.

11. Tarsio JR, Wignes B, Rhode TO, Rupp WM, Buchwald H, Furcht LT (1985) Nonenzymatic glycation of fibronectin and alteration of cell matrix basement membrane components in diabetes mellitus. Diabetes 34: 477-484.

12. De Giorgio LA, Bortolomei G, Gironi A, Caselli P, Seghieri G (1988) Increased plasma fibronectin con- 
centration in diabetic patients with microalbuminuria. Diabetes Care 11: 527-530.

13. Skrha J, Vackova I, Kvasnicka J, Stibor V, Stolba P, Richter H, Horman H (1990) Plasma free N-terminal fibronectin $30-\mathrm{kDa}$ domain as a marker of endothelial dysfunction in type 1 diabetes mellitus. Eur J Clin Invest 20: 171-176.

14. Lamberton RP, Goodman AD, Kassoff A, Rubin CL, Treble DH, Saba TM, Merimee TJ, Dodds WJ (1984) Von Willebrand Factor (VIII R: Ag), Fibronectin and insulin-like growth factors I and II in diabetic retinopathy and nephropathy. Diabetes 33: 125-129.

15. WHO Technical Report Series (WHO Expert Committee on diabetes mellitus: second report), No. 646, 1980.

16. WHO Technical Report Series (Diabetes Mellitus, Report of a WHO Study Group), No. 727, 1985.

17. Bykowska K, Wegrzynowicz Z, Lopaciuk S, Kopec $M$ (1985) Effect of proteolysis on quantitation of plasma fibronectin concentration by two immunoassays (Electroimmunoassay and Immunoturbidimetric Technique). Tromb Haemostas 53: 377-380.

18. Davis JE, McDonald JM, Jarrett L (1978) A highperformance liquid chromatography method for hemoglobin A1c. Diabetes 27: 102.

19. Gil FS, Schier GM, Moses RG, Gan JET (1985) Improved estimation of fructosamine as a measure of glycated serum protein with the Technicon RA-100 Analyzer. Clin Chem 21 (12): 2005-2006.

20. Tutle KR, Stein JH, De Fronzo RA (1990) The natural history of diabetic nephropathy. Seminars in Nephrology 10 (3): 184-193.

21. Takahashi M, Mizuno K, Tani M, Hayashi A, Nimura S, Fukuchi S (1991) Increased urinary fibronectin excretion in diabetic patients with microalbuminuria. Diabetes (Suppl 1) 40: 326A.

22. De Giorgia LA, Seghieri, Gironi A, Memmini P, Bartoli U, Bartolomei G (1984) Raised fibronectin concentration is related to the presence of diabetic retinopathy. Acta Diabetol Lat 21: 251-256.

23. Nardelli GM, Guastamachia E, Di Paolo S, Lacasella R, Balice A, Montedoro P, Cospite MR, Giorgina R (1987) Plasmatic levels of fibronectin in diabetic with and without retinopathy. Correlation with some hormonal and metabolic parameters. Acta Diabetol Lat 24: 255-262.

24. Seghieri G, Bartolomei G, De Giorgia LA (1986) Plasma fibronectin in diabetic retinopathy and macroangiopathy. Diabete Metab 12: 186-190.

25. Schwartz HP, Schernthaner G (1982) Influence of metabolic long term control (HbA1) on plasma fibronectin in insulin-dependent diabetics. Diabetes 31 (Suppl 2): 25A.

26. Borkenstein M, Muntean W (1988) Fibronectin and Von Willebrand Factor in children and Adolescents with Type 1 Diabetes. Pediatr Adolesc Endocrinol (Karger, Basel), 17: 18-23.

27. Davis TME (1981) Plasma fibronectin concentration in diabetes and the effect of short-term, improved glucose control. Diabetologia 21: 262 (Abstract).

28. Janka HU, Waldmann J, Mehnert H (1983) Plasma fibronectin and factor VIII related antigen in diabetic patients with atherosclerosis: The schwabhing study. Diabetologia 25: 167 (Abstract).

29. Clark RAF, Quinn JH, Winn HS, Lanigan JM, Dellepella P, Colwin RB (1982) Fibronectin is produced by blood vessels in response to injury. J Exp Med 156: 646-651.

30. Giralamo ND, Underwood A, McCluskey PJ, Wakefield D (1993) Functional activity of plasma fibronectin in patients with diabetes mellitus. Diabetes 42: 1606-1613.

31. Kouri TT, Viikari JSA, Mattila KS, Irjala KMA (1991) Microalbuminuria. Diabetes Care 14: 591-593.

32. Tomaselli L, Trischitta V, Vinci C, Frittitta L, Squatrito S, Vigneri R (1989) Evaluation of albumin excretion rate in overnight versus 24 -h urine. Diabetes Care 12: 585-587. 